final sentences of their letter and the correction: it is the same as saying that "a doubt has been raised by analysis 4.14 regarding a potential link (between the placebo-maintenance 10\% dextrose infusion-and NEC), and this warrants further research. Pending such safety studies, maintenance dextrose should only be used with caution in preterm infants." This is a statement that is clearly illogical nonsense, yet no more illogical than what they actually say in the final sentences of their letter and their correction. ${ }^{12}$

\section{S Richmond}

Correspondence to: Dr S Richmond, Neonatal Unit, Sunderland Royal Hospital, Kayll Road, Sunderland SR4 7TP, UK; sam.richmond@talk21.com

Competing interests: None.

Accepted 4 July 2008

\section{REFERENCES}

1. Khashu M. In neonates requiring intravascular volume resuscitation is the use of gelofusine safe and efficacious? - author's reply. Arch Dis Child 2008:93:264.

2. Correction. Arch Dis Child 2008;93:265

3. Osborn DA, Evans N. Early volume expansion for prevention of morbidity and mortality in very preterm infants. Cochrane Database Syst Rev 2004;(2):CD002055.

\section{BOOK REVIEW}

\section{Emergencies in paediatrics and neonatology}

Edited by Stuart Crisp, Jo Rainbow. Published by Oxford University Press, Oxford, 2007, pp 352, f19.95 (soft cover) ISBN 978-0-19-856866-7

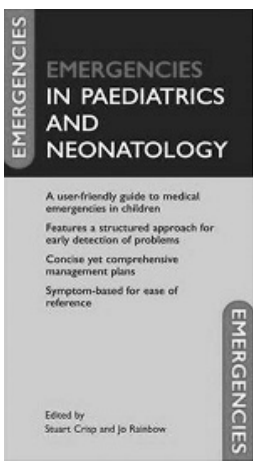

Presented in the reassuringly familiar Oxford Handbook format, this pocket sized publication aims to provide clear and simple but definitive early management strategies for anyone assessing and/or managing acutely unwell children. We "field tested" the book in our busy paediatric emergency department in London and although some of us had a few relatively minor issues with it, in general it got the thumbs up, particularly from the more junior doctors and nurses. It didn't fall apart either.

The book starts with a concise, informative and eminently sensible chapter entitled "Coping with patients and parents" which is essential reading for people new to paediatrics - preferably before their first shift. The other bit to read before starting work is the psychiatry chapter which, as well as dealing with specific mental illnesses and touching on child abuse, also has some very pertinent tips on communicating with young children and adolescents.

The subject matter is set out in topic-based chapters, some written by general paediatricians and some by specialists. Most chapters are written with the emergency doctor in mind, but others (eg, orthopaedics and general surgery) are written with a rather surgical bent which is perhaps less helpful for the front line emergency clinician. Rectal bleeding is dealt with under "Surgery" which means infective diarrhoea doesn't get a mention and similarly, despite being the most common cause of hip pain we see, transient synovitis is not described in the hip pain section under "Orthopaedics".

Although the title of the book suggests that it is going to describe emergencies on the neonatal unit, actually it is only the pathology likely to present to the emergency department which is covered in the Neonatal chapter. The point, however, is well made that with the current trend for early postnatal discharge, we do now see a large number of newborn babies arriving in from the community. Jaundice is one of the most common things we deal with in newborns. The chapter on that topic guides the junior clinician well, although I struggled with the phrase "term infants can tolerate [bilirubin] levels up to $300 \mu \mathrm{mol} / \mathrm{L}$ at day 1 of life". It would be disastrous if the unknowing junior clinician were to tolerate levels of $300 \mu \mathrm{mol} / \mathrm{L}$ in the first 24 hours as well. Indeed, there are other examples within the book, particularly in the normal values appendix, of quite "gungho" upper and lower limits of normality which made even me, as a pretty laid back sort of acute paediatrician, sweat a bit. A haematocrit of $75 \%$ in a newborn may not lead to sequelae it is true, but I don't know many neonatologists who would accept $75 \%$ as normal and not have their fingers at least twitching towards the partial exchange transfusion pack. There are very few references throughout the book and I was unsure where these normal values in particular came from.

There are a couple of misleading typos which need to be changed for future editions, one unfortunately in the example given for working out intravenous fluids and one in the chapter on neck lumps where an error in bulleting makes it look like all children with lymphadenopathy need referring to an oncologist. Inevitably, there have been a few NICE guideline changes since this book was written. Annoyingly for the UK clinician, blood gas values throughout the book are in $\mathrm{mm} \mathrm{Hg}$ instead of $\mathrm{kPa}$. All relevant practical procedures are described, but we felt that diagrams would have made the instructions easier to follow. Resuscitation is covered well and it is handy to have the algorithms in one's pocket. However, some of us would have liked to see a bit more information than just the APLS algorithms reproduced. Once we've used adrenaline, for example, for an allergic reaction, for how long should we observe the child? I suspect that many of the contributors to this book are young enthusiastic consultants, and registrars in our department felt that some chapters lacked the wisdom of more seasoned senior paediatricians.

Minor niggles aside, overall the reaction to this book in our emergency department was positive. It has been extremely useful for teaching. It helped junior staff and medical students take more directed histories and the nurses also rated it highly for its synopses of what they needed to know. It certainly has a place on the bookshelf of an emergency department or GP consulting room; even as a fairly experienced paediatric registrar, I missed it the day I left it at home.

Julia Thomson, Homerton Hospital, Homerton Row, London E9 6SR, UK; juliathomson@tesco.net

\section{CORRECTION}

doi:10.1136/adc.2005.081836corr1

F Bacopoulou, L Henderson, S G Philip. Menkes disease mimicking non-accidental injury. Arch Dis Child 2006;91:915. This article was originally published with an incorrect digital object identifier (doi). It has been updated with the correct doi: 10 . 1136/adc.2005.081836. We apologise for any inconvenience caused. 